\author{
Ahmed Atef Shaheen. \\ Email: ahmed.shaheen@aast.edu \\ Arab Academy of Science, Technology \& Maritime Transport (AASTMT), \\ P.O.Box 1029. \\ Mohamed Abbas Elkalla \\ Email: Mohamed.elkalla@aast.edu \\ Arab Academy of Science, Technology \& Maritime Transport (AASTMT), \\ P.O.Box 1029
}

\title{
Assessing the Middle East Top Container Ports Relative Technical Efficiency
}

\begin{abstract}
Middle East main container ports are developing rapidly with a lot of investments. This is due to their geographical location in the main East-West trade route. Accordingly, it is important to assess their relative technical efficiency to make them visible and stand out in such a development. This research will assess the relative technical efficiency based on the infrastructure of the main container ports in the Middle East by the aid of data envelopment analysis (DEA) for the year 2017. This will be performed by using the DEA four models based on the input oriented mode CCR model, BCC model, Supper efficiency and the Slack variable analyses. Results of the research highlight that nearly $80 \%$ of the studied ports are, with an increasing return to scale approach to the study ports, suffering from a surplus in their infrastructure that should be considered in future investments.
\end{abstract}

Keywords: Data Envelopment Analysis (DEA), Port Operating Efficiency, Container Ports, infrastructure

\section{Introduction}

The Middle East is considered an important region for the liner trade and in particular for container shipping lines. The importance of this region is based on the geographical position of the Middle East as it lays on the main east-west trade route between Asia and Europe. Moreover, this area is famous for its natural resources, in particular oils that make most of these countries capable of creating demand for the merchandised trade at an increasing pace. Container ports in this region are competing and investing a lot of money to attract this container traffic and therefore it could be 
very important to know their efficiency and to evaluate ports infrastructure capabilities in determining their competitiveness and ranking.

This research will use the data envelopment analysis (DEA) to benchmark the main container ports in the Middle East, based on their ranking among the top 100 ports worldwide. Accordingly, the research will use the cross section data for the year 2017 to assess the study ports relative technical efficiency based on their infrastructure. Firstly, the area of this study and selected ports will be presented including the research limitations. Secondly, previous researches that used DEA models will be reviewed. Thirdly, the DEA models results and analyses will be presented. Finally, the conclusion and recommendations of the research will be made.

\section{Area of study and research limitations}

In order to support the trade-oriented economic development, port managers are increasingly under pressure to improve port efficiency by ensuring the provision of port services on an international competitive basis; the 9 ports out of 100 top container ports in 2017 that are studied in this research are located in the Middle East as shown in Figure 1. These countries have seaports in critical geographical locations on the route of the international maritime trade between East and West. These ports are considered to be the main ports in the transport of goods from Europe and the Far East and vice versa owing to strategic location of some seaports that encourages modern vessels to make short calls between them to exchange goods. This area is the middle of the rope, linking the eastern side and the western side of the world by sea routes, and is currently witnessing economic growth in various fields. The nine container ports selected for this research have different policies, administrative and organizational structures. The organization of ports is not only different, but the size of ports also varies widely. The productivity varies from 1.5 to 15 million TEUs. Accordingly, the selected ports are presented as follows:

DUBAI, JEDDAH, SALALAH, PORT SAID, BANDAR ABBAS, KHORFAKKAN, KING ABDULLAH, ALEXANDRIA and DAMMAM.

This research will be limited to the assessment of the top Middle East container ports within the top 100 container ports worldwide for the year 2017. It will be also limited to benchmarking ports technical efficiency based on ports infrastructure. The data will be based on the cross section data for the year 2017. 


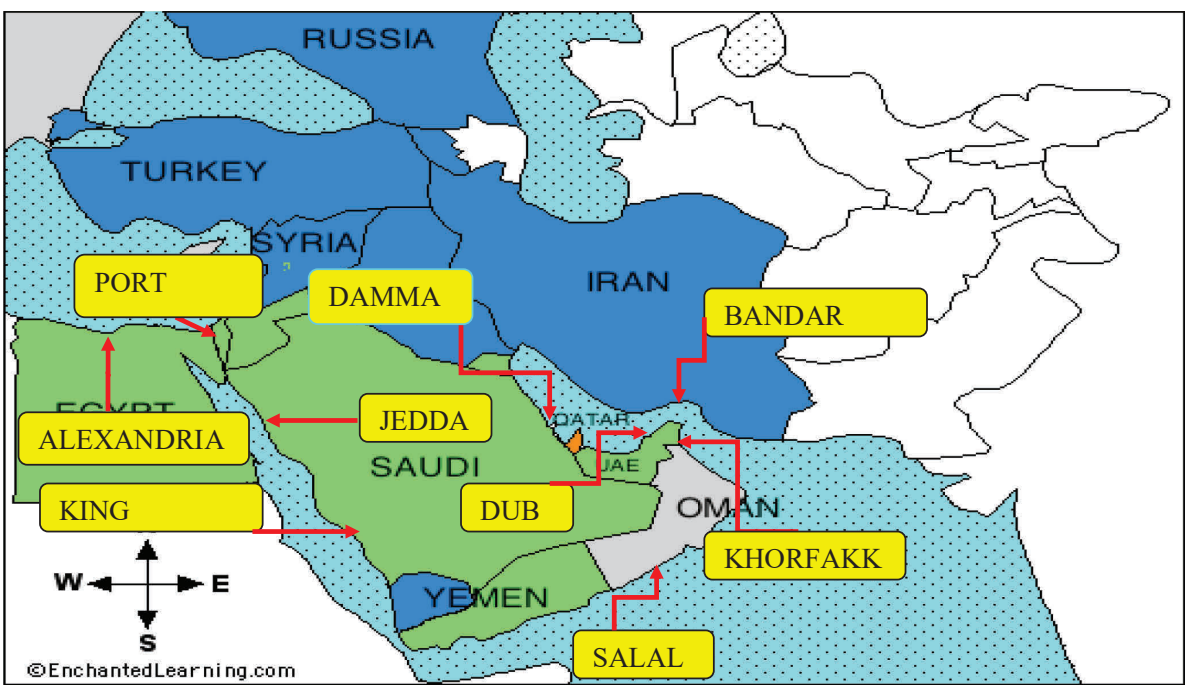

Figure 1 - Location of study ports (source by author)

\section{Previous researches}

The decision for port development, taken as per analysis of existing situation by getting strength, weakness, opportunities and threats (SWOT) analysis to find out strengths, weaknesses, opportunities and threat efficiency evaluation, allows for adopting suitable response measures (Liu, C-C., 2008). Consequently, the efficiency measurement off benchmarking could be a powerful tool (Park \& De, 2004). Efficiency is a relative thought that required evidently known benchmark to compare between ports and also self-performance through the time (Liu, Q., 2010).

In the maritime sector, many studies pertain to the frontier models to benchmark efficiency; nowadays researches investigate the development for ports efficiency to value the ports efficiency in respect of the estimated ports competency, in addition to the technological operational improvement and innovation accomplishments. However, the efficiency and ports production were promoted because of the change in ports structure and organization as an effect of change in ports operation character (Gonzalez and Trujillo, 2009)

Beatriz L., et al (2019) studied the efficiency and productivity for 20 Brazilian container ports between the years 2008 to 2017 via The Stochastic frontier analysis. This research uses the two concepts. He declared that efficiency and productivity in an equivalent way approximate the measurement of the efficiency of businesses by fractional productivity indicators, which are ratios among the product and a factor. To 
estimate productivity, two significant applications are derived: one includes gaining its chronological evolution and the other one infringement of the growth inside productivity on its main fundamental factors, wherever efficiency changes engage in the recreation of an important part. From a different viewpoint, efficiency in production supports the comparison among a company's definite and optimal performance. The best objective that the company could achieve is based on an accurate proof of optimal outcomes reached by other companies.

The scope and objective of researches have changed over time. The purpose of studies involves efficiency, relative efficiency tested for benchmarking ports, therefore ports owner ship and organization structure checked for port efficiency; the way to examine efficiency for ports made by Stochastic Frontier Analysis (SFA) and (DEA) Analysis. The methodology used depends on hypotheses of objectives considered by each study in this situation. Cullinane et al. (2005) checked the development of efficiency for container ports by means of panel data with DEA for benchmarking efficiency as the effect of improving the efficiency of container port in study probably traced eventually. Wanke et al. (2011) employ DEA and SFA for collected data from 25 Brazilian ports in 2008 and the presented result for Brazilian ports contain shortage in capacity because of the increase of the export during the last few years and shortage of investments for developing capacity.

Bichou (2013) uses DEA model to evaluate operational efficiency in the period between 2004 to 2010 for 420 main container terminals and the study formed a number of operational suggestion to examine sensitivity for benchmarking the outcome to port market for example; production scale, operating configurations, cargo mix , transshipment ratio, and working procedures. The results discovered that variations in operating conditions significantly affect terminal efficiency. Otherwise, $\mathrm{Lu}$ et al. (2015) studied technical efficiency to benchmark the top 20 container ports worldwide in 2009 using the DEA models. They completed the container ports study demonstrating that there exists substantial desecration in the production procedure.

The efficiency of the port market has developed abnormally over time because of technological changes and developments in marine and seaport innovations. Many researchers have attempted to study the relationship between the size and efficiency of ports (Cullinane et al., 2002 and Sohn \& Jung, 2009). In general, they concluded that port efficiency is largely related to its size due to the level of activity in ports.

In this context, according to Martinez-Budria et al. (1999) Spanish port authorities are sorted into three groups (large, medium and small); they applied the complexity criteria that take into account the size of the port, and the output vector constitution and examined the efficiency of the port via the DEA model. They determined that the larger ports are the more efficient ones while the medium-sized ports are the least efficient. Wang and Cullinan (2006) applied the anti-drug management models to 104 European stations with a production rate of more than 10,000 TEUs in 2003; the study 
revealed that the maximum container ports with a large production scale also had a high degree of efficiency.

In addition, Sohn and Jong (2009) noted that great Asian ports with the largest share of transshipment operations are more efficient than the secondary ports on the same market. On the opposite, Coto-Millan et al. (2000) use an AND analysis model to assess the efficiency of seaports in 22 ports in the Middle East and East Africa. They concluded that secondary outlets were more efficient than large outlets, but highlighted that this market suffered from instability due to instability in the region, and thus the ports were heavily affected. They examined as well the effect of port size on port efficiency by studying port capacity.

On the other hand, Coto-Millan et al. (2000) assessed the competence of port authorities and tried to determine whether the type of organization and the size of the port could justify the observed differences in economic efficiency measures. They found that the large ports in their studies are less efficient than the small ports. However, after examining the various elements that could affect the degree of economic efficiency, they declared that port size is not the main factor in assessing economic efficiency.

Notteboom et al. (2000) use the approach of comparing the technical efficiency of the major container terminals in Europe with the four largest Asian container terminals. They studied the impact of many components that could affect operational efficiency including the size of terminal, ownership structure (private or public), key services (hub or spoke), and geographical location (Northern Europe and Southern Europe). They concluded that the smaller terminals inside the port were more efficient because of the intense competition between them. In addition, they also emphasized that the hub is more efficient than the feeder because of the competition between the ports.

Moreover, Gonzalez \& Trujillo (2009) concluded that hub ports are investing heavily in developing their super/high structure to reach their expected growth for future demand which could lead to increased capacity at the time of such investment. Therefore, satisfactory levels of efficiency can be achieved. Moreover, while many large ports reach the maximum growth limit and cannot achieve greater efficiency, smaller ports can find opportunities and take the lead for further growth and access to optimal standards. Consequently, they stressed that all these factors made it difficult to establish a rational relationship among efficiency and port size.

The impact of regulatory structures and property and management systems on port efficiency gradually became a subject of interest to transport researchers. Valentine and Gray (2001) applied the DEA model to 31 container ports between the world's top 100 container ports in 1998 to study the relationship between port efficiency and explicit types of ownership and firm structures. The study concluded that these relationships lead to advanced efficiency. Cullinan et al. (2002) concentrated on the structure of ownership and privatization of the public sector. He concluded that the deregulation level had a 
positive impact on port efficiency, and that the privatization of ports at major container terminals in Asia had positively affected their economic efficiency at the terminals. They also noted that the size and efficiency of the terminal are directly linked.

Collinan and Soong (2003) concluded that the higher the level of private sector participation in the operation and management of the port, the greater the level of efficiency. However, they noted that according to increased competition in the South Korean market there has been enhanced terminal efficiency. Cullinane et al. (2006) applied two processes of DEA and stochastic production limits on the world's top container ports to analyze the impact of privatization on port efficiency. The study concluded that the most efficient ports are those with a high proportion of private participation that have been confirmed from Singapore Port.

Gonzalez \& Trujillo (2009) concluded that there is no harmony on whether there is a relationship among port ownership and efficiency, but the efficiency of port/container terminals has been strengthened with the increasing trend towards privatization. Wanki (2013) studied in 2011 the efficiency of 27 Brazilian ports using two degrees of analysis. The first one was the efficiency of the infrastructure, followed by the efficiency of assembling the shipments. They concluded that private sector management policy provided higher levels of physical infrastructure efficiency.

$\mathrm{Lu}, \mathrm{B}$, et al. (2015) applied three types of DEA models to check the operational efficiency of the world's most important container ports. Their objective was to provide port operators with the understanding of allocating resources as well as improving operational performance. This research identifies the cause of inefficiency, identifies potential areas to enhance inefficient ports using random variables technology, and uses the return to scale approach to measure whether the port is in an increase, decrease or constant return to a scale. Finally, a sensitivity analysis was applied to determine which inputs or outputs were more important variables of the model and had an impact on the results of the study.

Suarez-Alemán et al. (2016) examined the performance analysis of the container port in the developing world from 2000 to 2010, using parametric and atypical methods in 70 developing countries, including 203 ports. They concluded that productivity growth rates in the study period differed greatly and that this variation was described by pure efficiency changes rather than by the wide efficiency of technological changes. In addition, it undertakes a comprehensive analysis of the effectiveness of the reasons for port efficiency. They also found an upward trend in port efficiency in developing regions, rising from $51 \%$ in 2000 to $61 \%$ in 2010 .

Kutin N., et al. (2017) examines the relative competencies of 50 container ports and terminals. These ports are categorized on their own container handling system and their location uses the DEA method with production-oriented data, and the superior efficiency is assessed with fixed returns to distinguish the efficiency of the frontiers. The main objective was to help port managers make choices on increasing container traffic and to improve operations and improve ASEAN transit network. 
Merkel and Holgermann (2017) use a composite dataset of port efficiency calculations from 52 studies and decline these calculations for the characteristics of ports and country. They concluded that there was a lack of paid care for the port service and that they had critical inferences to understand efficiency estimates. At the country level, there is a negative correlation between GDP per capita and calculated port efficiency, and a negative correlation between intra-port competition and discretionary efficiency. The research discusses the interpretation of these results in the context of partial production functions, and argues that a large share of applied methods does not replace the substitution between product and user inputs.

\section{Methodology}

DEA can be defined almost as a non-parametric method for measuring the efficiency of a decision-making unit (DMU) with multiple inputs and/or multiple outputs. This is achieved by creating one "default" output to one "default" entry without a predefined production function. The expression DEA and CCR were first formulated by Charnes et al. (1978), which was followed by a massive expansion of DEA in terms of its theory, methodology and application over the past few decades. Among other models in the DEA context, the most widely used DEA, DEA-CCR and DEA-BCC, deserve more attention. The DEA-CCR assumes steady returns for measurement so that all observed production groups can be increased up or down proportionately.

While Infante and Gutiérrez (2013) described that DEA method was used to assess production efficiency on field, however, in the current research they are used to assess the relative technical efficiency among container ports where they have been widely used for this purpose in various researches.

$$
\text { Efficiency }=\text { Total Output } / \text { Total Input }
$$

In general, efficiency can be described as follows:

$$
\begin{aligned}
& \text { Or } \\
& \mathrm{E}=\frac{\sum_{\mathrm{i}}^{\mathrm{N}}=0^{\mathrm{v}_{\mathrm{i}} \mathrm{i}}}{\sum_{\mathrm{i}}^{\mathrm{N}}=0^{\mathrm{u}} \mathrm{i}^{\mathrm{x}} \mathrm{i}}
\end{aligned}
$$

Where $\mathrm{E}$ is efficiency and $\mathrm{xi}$, yi are input and output, while $u i$ and VI are factors referring to factors that describe the relative significance of each factor. The competency assessment usually involves many inputs and outputs; therefore, they should be selected in relation to the nature of the study problem. Methodologically, the DEA model search planning, in which the agents are detected, is not only related to efficiency analysis based on DEA models, but is also linked to a different proposal 
to improve efficiency (Infante \& Gutiérrez, 2013). The above explanation of DEA technology provides an indication of its main features.

\subsection{DEA models and the procedures of efficiency analysis}

From the literature reviewed earlier, it was apparent that many studies used DEA (DEA-CCR and DEA-BCC) models in all areas, including developed, emerging or international markets, despite the technology gap or system management between them. (Amroznig et al., 2008). Therefore, this research applies mainly to these models. Wang et al. (2003) noted that the model orientation reflects the scope of research. For example, input-oriented models are related to operational and management aspects, while output-oriented models are more closely relevant to the planning and strategy creation.

The official standard of mathematical measurement for different DEA models can be found in Cooper et al. (2002). For the purposes of the analysis presented here, however, it is sufficient to recall that the output-oriented management model seeks to increase the relative increase in production while remaining within the range of production potential. The efficiency-oriented measurement problem can be written as a series of linear packaging problems for programming $\mathrm{K}$, with the distinction between the DEA-CCR and DEA-BCC.

DEA-CCR and DEA-BCC technical efficiencies are often used to obtain a measure of the efficiency of scale for the DMU unit it has provided. The efficiency of the scale indicates inadequate measurement (Cooper et al., 2002). The inadequacy of the scale is due to the increase or decrease of returns to the scale, which can be determined by examining the total weights, under the CCR model specifications. If this amount is equal to one, the Fixed Revenue Act prevails on the scale, while the returns on the scale increase and the returns on the scale decrease when the sum, respectively, amounts to less or more than the unit.

This research will use the nonparametric DEA models for the assessment of ports technical efficiency for selected ports infrastructure. This will be performed by using the DEA four models based on the input oriented mode:

- CCR model to assess ports aggregate technical efficiency

- BCC model to assess the pure technical efficiency

- Supper efficiency to discriminate the efficient ports

- Slack variable analyses to identify the potential improvement values of ports input variables 


\section{Efficiency analysis of the selected Middle East ports}

\subsection{CCR and BCC analysis}

Table 2 - The CCR, BCC and scale efficiency results

\begin{tabular}{|l|c|c|l|}
\hline Unit name & \multicolumn{1}{|l|}{ CCR } & BCC & Scale \\
\hline Dubai & $100 \%$ & $100 \%$ & Constant \\
\hline Salalah & $100 \%$ & $100 \%$ & Constant \\
\hline Bandar Abbas & $81 \%$ & $100 \%$ & Increasing returns \\
\hline Khorfakkan & $73 \%$ & $94 \%$ & Increasing returns \\
\hline Port Said & $72 \%$ & $98 \%$ & Increasing returns \\
\hline Alexandria & $68 \%$ & $100 \%$ & Increasing returns \\
\hline Jeddah & $56 \%$ & $88 \%$ & Increasing returns \\
\hline Dammam & $53 \%$ & $100 \%$ & Increasing returns \\
\hline King Abdullah & $45 \%$ & $85 \%$ & Increasing returns \\
\hline
\end{tabular}

Table 2 shows that for the CCR model the results are showing 2 efficient models where Dubai \& Salalah retain their efficiency position, while the least efficient ports are Dammam and King Abdullah. For the BCC models we have three efficient ports that are the two efficient ports in the CCR model in addition to Bandar Abbas. Moreover, Alexandria is showing significant results when the $\mathrm{BCC}$ and $\mathrm{CCR}$ results are compared as it is showing poor efficiency scores for the aggregated value efficiency, while it is showing efficient results for the pure technical scores.

Regarding the Scale efficiency that represents the capability of increasing efficiency, if there is a constant return to scale and the inputs are doubled, the outputs will also be doubled. For the increasing return to scale throughputs will increase more than double the doubled inputs, while for the reduced return to scale the outputs will be less than doubled when the inputs are doubled.

Accordingly, our previously analyzed figures clearly show that there are only 2 constant returns to scale ports which are Dubai and Salalah, while the remaining ports are showing increasing return to scale figures. This is a good indicator in which, when the less efficient ports are developed, the return for ties developments will be more than expected in terms of ports outputs. 


\subsection{Super efficiency results}

Table 3 - Super efficiency scores of the efficient ports

\begin{tabular}{|l|c|c|l|}
\hline Unit name & CCR & BCC & BCC - Super efficiency \\
\hline Dubai & $100 \%$ & $100 \%$ & $1000 \%$ \\
\hline Salalah & $100 \%$ & $100 \%$ & $158.8 \%$ \\
\hline Alexandria & $68 \%$ & $100 \%$ & $153.5 \%$ \\
\hline Dammam & $53 \%$ & $100 \%$ & $131.9 \%$ \\
\hline Bandar Abbas & $81 \%$ & $100 \%$ & $101.9 \%$ \\
\hline
\end{tabular}

When calculating the super efficiency scores to discriminate between the efficient ports, it is clear (as shown in Table 3) that Dubai port is the most efficient port, while Bandar Abbas is the least efficient one.

\subsection{Slack variable analysis}

Slack variable analyses are considered to find out the percentage of a variable to be added to convert the DMU from the status of inefficient to the efficient one. Figure (2) shows that all 3 input variables are showing equal percentages of contribution in the efficiency score results and, likewise, all variables should be improved by nearly $1 / 3$ by shifting all the study ports from inefficient to the efficient port status. The collective data that identify the overall improvement variable sectors with the detailed improvement for each port variable will be presented in Table 4 .

Table 4 shows that all ports (except for the efficient ports) are suffering from surplus in their infrastructure with the exception for ports of Dubai and Salalah. Port of King Abdullah is the highest placed port in terms of the required reduction in its infrastructure. As for the quay length results, the port of Dammam is showing a surplus in its quay length by nearly $68 \%$ that means that the ports should stop investing in any quay length development plans. Moreover, as for the ports total area, the Bandar Abbas port is the least one in terms of excess land areas, and this port should stop investing in any land expansion plans so it could increase its relative technical efficiency. Finally, it is clear that nearly $80 \%$ of the study ports are having a surplus in their infrastructure which directly affects their relative technical efficiency scores. 


\section{$\operatorname{Max} \operatorname{Depth}(\mathrm{m})$}

\section{Quay lenght(m)}

Quay Length (m) -33.34\%

- Total Area(ha) $-35 \%$

Max Depth $-33.66 \%$

Throughput 2017 0\%

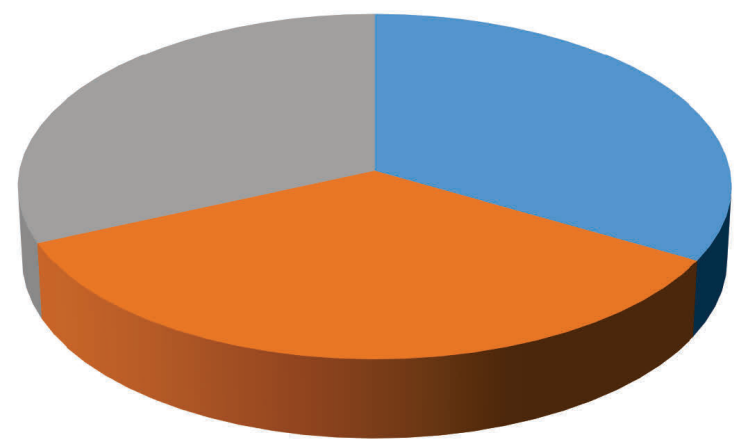

\section{Total Area(ha)}

Figure (2) - total improvement percentages for the total study ports

Table 4 - Improvement amount and percentage rate for each of the ports

\begin{tabular}{|l|c|c|c|c|c|c|}
\hline \multirow{2}{*}{ Port } & \multicolumn{2}{|c|}{ Target Max Depth } & \multicolumn{2}{c|}{ Target Total Area } & \multicolumn{2}{c|}{ Target Quay Length } \\
\cline { 2 - 7 } & $\%$ & $(\mathrm{~m})$ & $\%$ & $(\mathrm{ha})$ & $\%$ & $(\mathrm{~m})$ \\
\hline Dubai & 0 & 15.5 & 0 & 670 & 0 & 9737 \\
\hline Salalah & 0 & 18 & 0 & 95 & 0 & 2204 \\
\hline Bandar Abbas & -30.1 & 11.89 & -72.7 & 62.76 & -19.4 & 1455.96 \\
\hline Khorfakkan & -33.8 & 10.59 & -27.4 & 55.88 & -42.9 & 1296.43 \\
\hline Port Said & -27.7 & 10.49 & -27.7 & 88.23 & -28.2 & 1722.28 \\
\hline Alexandria & -47.4 & 7.36 & -31.8 & 38.83 & -42.7 & 900.83 \\
\hline Jeddah & -43.8 & 8.99 & -48.8 & 154.53 & -43.8 & 2527.86 \\
\hline Dammam & -47.7 & 7.22 & -47.1 & 38.09 & -68.7 & 883.73 \\
\hline King Abdullah & -54.7 & 7.48 & -59.8 & 42.19 & -54.7 & 952.12 \\
\hline
\end{tabular}




\section{Conclusion}

Middle East ports development and competitiveness could be easily addressed by evaluating their respective efficiency. The results of this research highlight that nearly $80 \%$ of the studied ports feature an increasing return to scale figures, which means that by adding more resources to the outcomes of ports development more efficient results will be obtained. Nonetheless, the study ports are suffering from surplus in their infrastructure (except for ports of Dubai and Salalah), which could be a result of geopolitical conflicts in the region. Moreover, the input variables showed an equal share or contribution to ports efficiency.

This highlights the need for more decisions in the regional scale to increase the regional ports efficiency. This can be performed by regional agreements between ports to carry out more cooperative measures. These ports can share resources to avoid ports individual investment strategies that can provide more resources in that sector with less efficient results.

\section{References:}

1. Beatriz L., María J., Freire-S., Fernando G.,(2019) Efficiency and productivity of container terminals in Brazilian ports (2008-2017) Utilities Policy, ISSN: 0957-1787, Vol: 56, Page: 82-91

2. Bichou, K. (2013) „An empirical study of the impacts of operating and market conditions on container-port efficiency and benchmarking ${ }^{\text {ee }}$. Research on transportation economics, 42 (1), 28 37.

3. Charnes A., Cooper W., Rhodes E., (1978): Measuring the efficiency of decision-making units, European Journal of Operational Research (2) 429 - 444.

4. Cooper W., Deng H., Huang Z., Li S.,(2002) A chance constrained programming approach to congestion in stochastic data envelopment analysis, European Journal of Operational Research, 53 , pp. 1-10

5. Coto-Millan, P., Banos-Pino, J., and Rodriguez-Alvarez, A. (2000) „Economic efficiency in Spanish ports: Some empirical evidencee , Maritime Policy and Management, 27 (2), 169-174. 302

6. Cullinane K., Wang T., Song D., Ji P.,(2006) The technical efficiency of container ports: Comparing data envelopment analysis and stochastic frontier analysis, Transportation Research Part A: Policy and Practice, Vol. 40, Issue 4, pp. 354-374

7. Cullinane, K.P.B. (2002) ,The productivity and efficiency of ports and terminals: methods and applications"e. In: Grammenos, C.T. (ed.) the Handbook of Maritime Economics and Business, pp. 803-831. LLP, London.

8. Cullinane, K.P.B. (2002) „The productivity and efficiency of ports and terminals: methods and applications se. In: Grammenos, C.T. (ed.) the Handbook of Maritime Economics and Business, pp. 803-831. LLP, London.

9. Cullinane, K.P.B., and Song, D-W. (2003) „A stochastic frontier model of productive efficiency of Korean container terminalse. Applied Economics, 35, 251-267.

10. Cullinane, K.P.B., Song, D-W., and Wang, T-F. (2005) „The Application of Mathematical Programming Approaches to Estimating Container Port Production Efficiencye, Journal of Productivity Analysis, 24, 73-92. 
11. Gonzalez, M.M., and Trujillo, L. (2009) „Efficiency Measurements in the Port Industry: A Survey of the Empirical Evidence ". Transport Economics and Policies, 43 (2), 157-192. 310

12. Infante, Z., and Gutiérrez, A. (2013) Port Efficiency in APEC. México y la Cuenca del Pacífico. Enero - abril de 2013. Análisis.

13. Kutin N., NguyenT., Vallée T., (2017) Relative Efficiencies of ASEAN Container Ports based on Data Envelopment Analysis, The Asian Journal of Shipping and Logistics, Vol. 33, Issue 2, pp. 67-77.

14. Liu Q., (2010) Efficiency Analysis of Container Ports and Terminals, (Unpublished doctoral dissertation) College of London, UK.

15. Liu, C-C. (2008) „Evaluating the operational efficiency of major ports in the Asia-Pacific region using data envelopment analysis ${ }^{\text {ee }}$. Applied Economics, 40, 1737-1743.

16. Lu, B., Park, N.K., and Huo, Y. (2015) 'The Evaluation of Operational Efficiency of the World's Leading Container Seaports'. Journal of Coastal Research, 73 (sp1), 248-254.

17. Lu, B., Park, N.K., and Huo, Y. (2015) 'The Evaluation of Operational Efficiency of the World's Leading Container Seaports'. Journal of Coastal Research, 73 (sp1), 248-254.

18. Martinez-Budria, E., Diaz-Armas, R., Navarro-Ibanez, M., and Ravelo-Mesa, T. (1999) „A Study of the Efficiency of Spanish Port Authorities Using Data Envelopment Analysise. International Journal of Transport Economics, 26 (2), 237-253.

19. Merkel A., Holmgren J., (2017), Dredging the depths of knowledge: Efficiency analysis in the maritime port sector, Transport Policy, Vol. 60, pp. 63-74

20. Notteboom, T.E., Coeck, C., and Van den Broeck, J. (2000) „Measuring and explaining the relative efficiency of container terminals by means of Bayesian Stochastic Frontier Models ${ }^{\text {ee }}$. International Journal of Maritime Economics, 2 (2), 83-106.

21. Sohn, J.-R., and Jung, C.-M. (2009) „The size effect of a port on the container handling efficiency level and market share in international transshipment flow" ${ }^{\text {ee }}$. Maritime Policy and Management. $36(2), 117-129$

22. Suárez-Alemán A., Sarriera M., Serebrisky T., Trujillo L.,(2016), When it comes to container port efficiency, are all developing regions equal?, Transportation Research Part A: Policy and Practice, Vol. 86,pp. 56-77

23. Valentine, V.F., and Gray, R. (2001) „The measurement of port efficiency using data envelopment analysis"e. In: Proceedings of the 9th World Conference on Transport Research. Seoul, South Korea.

24. Wang, T.-F., Cullinane, K., and Song, D.-W. (2003) „Container port production efficiency: a comparative study of DEA and FDH approache. Journal of the Eastern Asia Society for Transportation Studies, 5, 698-713.

25. Wang, Y., and Cullinane, K.P.B. (2006b) „Inter-port competition and measures of individual port accessibility ${ }^{\text {ee }}$. Proceeding of the 7th International Association of Maritime Economists Annual Conference, 12-14 July, Melbourne.

26. Wanke, P. (2013) „Physical infrastructure and shipment consolidation efficiency drivers in Brazilian ports: A two-stage network-DEA approach"e. Transport Policy, 29, 145-153.

27. Wanke, P.F., Barbastefano, R.G., and Hijjar, M.F. (2011) „Determinants of Efficiency at Major Brazilian Port Terminalse. Transport Reviews, 31 (5), 653-677. 
